\title{
Ehrlichia canis e Anaplasma platys em carrapatos de cães de Cuiabá, Mato Grosso
}

\section{Ehrlichia canis and Anaplasma platys in ticks of dogs in Cuiaba, Mato Grosso}

\author{
Arleana do Bom Parto Ferreira de Almeida ${ }^{1}$; Daphine Ariadne Jesus de Paula ${ }^{2}$; \\ Magyda Arabia Araji Dahroug'; Agrádia Gonçalves de Freitas³; José Nivaldo da \\ Silva ${ }^{4}$; Valéria Dutra ${ }^{5}$; Luciano Nakazato ${ }^{5}$, Valéria Régia Franco Sousa ${ }^{5 *}$
}

\section{Resumo}

Doenças transmitidas por artrópodes, como o Rhipicephalus sanguineus, são causadas por um espectro de patógenos. Dentre estas, estão a erliquiose monocítica canina e trombocitopenia cíclica com distribuição cosmopolita. Com o objetivo de verificar a presença de DNA de Anaplasma platys e Ehrlichia canis em carrapatos $R$. sanguineus coletados no período de 2008 a 2009 de 380 cães infestados. Os carrapatos, após a maceração, foram submetidos a extração de DNA e, em seguida, foi realizada a Nested PCR para a amplificação da espécie $A$. platys e E. canis. Destes, 81 (29.7\%) amplificaram o DNA dos agentes ehrlichiais, onde 38 (17.9\%) amplificaram para E. canis e 32 (15.7\%) para A. platys. A observação dos dois patógenos, combinado com distribuição mundial do carrapato $R$. sanguineus, demonstra o elevado risco de infecção por esses patógenos de cães na cidade de Cuiabá.

Palavras-chave: Ehrlichiose monocítica canina, trombocitopenia cíclica canina, Rhipicephalus sanguineus, PCR

\begin{abstract}
Diseases transmitted by arthropods such as Rhipicephalus sanguineus, are caused by a spectrum of pathogens. Among these are the canine monocytic ehrlichiosis and cyclical thrombocytopenia with a cosmopolitan distribution. Aiming to verify the presence of DNA of Anaplasma platys and Ehrlichia canis in ticks $R$. sanguineus collected in the period 2008 to 2009 of 380 infected dogs. Ticks, after maceration, were subjected to DNA extraction and then nested PCR was performed for amplification of A. platys and E. canis. Of these, 81 (29.7\%) amplified DNA from ehrlichiais agents, where $38(17.9 \%)$ amplified in E. canis and $32(15.7 \%)$ for A. platys. The observation of two pathogens, combined with worldwide distribution of the tick $R$. sanguineus, demonstrates the high risk of infection with these pathogens in dogs in the city of Cuiaba.

Key words: Canine monocytic ehrlichiosis, canine cyclic thrombocytopenia, Rhipicephalus sanguineus, PCR

1 Doutorando(s) do Programa de Pós-Graduação em Pesquisa Clínica em Doenças Infecciosas, Instituto de Pesquisa Clínica em Doenças Infecciosas, IPEC/FIOCRUZ, Rio de Janeiro, RJ. E-mail: arleferreira@gmail.com; magyda@gmail.com

2 Doutorando do Programa de Pós-Graduação em Ciências da Saúde, Universidade Federal de Mato Grosso, UFMT, Cuiabá, MT. E-mail: daphine.depaula@gmail.com

3 Médica Veterinária Autônoma. Cuiabá, MT. E-mail: dada.agradia@hotmail.com

4 MSc. Médico Veterinário, Universidade Federal de Mato Grosso. Pontal do Araguaia, MT. E-mail: pronto.vet@hotmail.com

5 Profs. Adjunto(s) do Dept ${ }^{\mathrm{o}}$ de Clínica Médica Veterinária, UFMT, Cuiabá, MT. E-mail: valdutra@ufmt.br; lucnak@ufmt.br;
\end{abstract} regia@ufmt.br

* Autor para correspondência 


\section{Introdução}

Os carrapatos são vetores de enfermidades de importância em saúde animal e humana (HARRUS et al., 2010). Característica como a capacidade de sobreviver em ambientes diversificados e por longo período sem se alimentar, além de uma ampla distribuição geográfica, faz desses ectoparasitos um dos mais importantes em termos de transmissão de doenças (DANTAS-TORRES, 2008). O carrapato vermelho do cão Rhipicephalus sanguineus, espécie mais difundida no mundo é importante vetor de patógenos caninos como Babesia vogeli, Ehrlichia canis, Hepatozoon canis, Rickettsia conorii e Rickettsia rickettsii (DANTAS-TORRES, 2008).

A importância, tanto econômica quanto de saúde pública, das doenças vinculadas por artrópodes tem impulsionado o diagnóstico dessas enfermidades no hospedeiro animal e nos vetores, sendo as técnicas moleculares as ferramentas diagnósticas mais empregadas para este fim (INOKUMA et al., 2003; HARRUS et al., 2010). No Brasil, as doenças vinculadas a artrópodes têm sido amplamente estudados nas populações, entretanto poucos estudos são realizados focando infecção nos carrapatos.

Diante deste quadro o presente estudo tem por objetivo avaliar a infecção de carrapatos parasitando cães da cidade de Cuiabá, região central do Brasil por Ehrlichia canis e Anaplasma platys, através da reação em cadeia pela polimerase.

No período de 2008 a 2009 foi realizado inquérito canino para investigação de leishmaniose em bairros da cidade de Cuiabá, estado de Mato Grosso, no qual obteve-se espécimes de carrapatos dos cães durante exame clínico. Os espécimes adultos foram acondicionados em microtubos, conservados em álcool $70^{\circ} \mathrm{GL}$ e encaminhados ao Laboratório de Leishmanioses do HOVET-UFMT, onde foram identificados segundo chave proposta por Aragão e Fonseca (1961) e posteriormente congelados a $-20^{\circ}$ $\mathrm{C}$ até o momento das análises.

Para a extração de DNA os carrapatos foram macerados e posteriormente, colocados em tampão de lise contendo $10 \mathrm{mM}$ Tris- $\mathrm{HCl}, \mathrm{pH} 8.0 ; 25 \mathrm{mM}$ EDTA; $100 \mathrm{mM} \mathrm{NaCl} ; 0.5 \%$ SDS e $100 \mu \mathrm{g} / \mathrm{ml}$ de proteinase $\mathrm{K}$, e incubadas a $56^{\circ} \mathrm{C}$ por 24 horas até completa lise celular. A seguir utilizou-se o método fenol-clorofórmio e precipitação por isopropanol. Após lavagem com etanol $70 \%$ por 10 minutos a $10.000 \mathrm{~g}$, o DNA foi ressuspendido em água ultra pura. A qualidade e integridade do DNA foram observadas em gel de agarose $1 \%$.

Os oligonucleotídeos sintéticos utilizados para a primeira etapa de amplificação para os dois agentes foram: ECC (5'-AGAACGAACGCTGGCGGCAAGCC-3') e ECB (5'-CGTATTACCGCGGCTGCTGGC-3') que amplifica para o gene $16 \mathrm{~S}$ e no nested $\mathrm{PCR}$ para amplificação da espécie E. canis foram ECAN (5'-CAATTATTTATAGCCTCTGGCTATAG-3') e

HE3

(5'-TATAGGTACCGTCATTATCTTCCCTAT-3'), que amplificam fragmentos de 458 e 398 pares de bases, respectivamente (MURPHY et al., 1998). Para o nested PCR de Anaplasma platys, foram utilizados os oligonucleotídeos iniciadores denominados Platys-F (5'-AAGTCGAACGGATTTTTGTC-3') e Platys-R (5'-CTTTAACTTACCGAACC-3'), os quais obtem-se amplicons de aproximadamente 504 pares de bases (INOKUMA et al., 2002). Os produtos amplificados foram submetidos à eletroforese em Gel de Agarose a 1.5\% corado com Brometo de Etídeo.

Para a análise estatística dos resultados obtidos, foram utilizados o teste do Qui-Quadrado e Teste Exato de Fischer, através do programa Epi info versão 3.3.2., tendo sido considerados significativos os resultados com significância $\mathrm{p} \leq 0,05$.

Dos 380 cães avaliados, 274 cães se encontravam infestados com carrapatos, sendo identificados como $R$. sanguineus. Dos espécimes coletados, 81 (29.6\%) amplificaram DNA de agentes ehrlichiais, onde $38(17.9 \%)$ amplificaram para Ehrlichia canis e $32(15.7 \%)$ para Anaplasma platys. Houve coinfecção entre os agentes em 11 (4.0\%) amostras, 
não sendo observada diferença estatisticamente significativa entre a infecção pelos dois agentes.

Dada a importância das doenças transmitidas por artrópodes na saúde animal e humana, infecções por agentes ricketsiais em carrapatos têm sido reportados em todo o mundo com prevalência bastante variável (INOKUMA et al., 2003; AKTAS et al., 2009). Nesta pesquisa $81(29.7 \%)$ dos carrapatos encontrados parasitando cães encontravam-se infectados, dado superior a outros estudos (MURPHY et al.,1998; INOKUMA et al., 2003; AKTAS et al., 2009). Tal disparidade pode estar associada com fatores climáticos, como a diversidade geográfica e climática, além do método de diagnóstico aplicado (AKTAS et al., 2009).

$\mathrm{Na}$ presente pesquisa, estudando os dois principais agentes da ehrlichiose canina, o encontro de $17.9 \%$ e $15.7 \%$ dos carrapatos com E. canis e $A$. platys, respectivamente, demonstram a circulação desses agentes nos carrapatos de cães da região e o potencial de transmissão para outros animais suscetíveis, fato que se correlaciona com estudos realizados anteriormente no município de Cuiabá, demonstrando prevalência de $42.5 \%$ em cães infectados por E. canis (SILVA et al., 2010), sendo infecção por $A$. platys já documentada (SOUSA et al., 2010).

Carrapatos da espécie $R$. sanguineus possuem grande importância na disseminação de patógenos de importância zoonótica, sendo reportado como vetor de E. canis. A observação apenas desta espécie parasitando cães domiciliados no município de Cuiabá corrobora com outros autores que demonstram a distribuição cosmopolita deste artrópode, com maior concentração em área urbana (DANTAS-TORRES, 2008). Por seu hábito hematófago, estes carrapatos apresentam sangue dos seus hospedeiros caninos, e a positividade na PCR, resulta na possibilidade de infecção do carrapato ou do cão infestado. Porém provê informações acerca da prevalência desses agentes na população canina da região (INOKUMA et al., 2003).
Anaplasma platys, agente da trombocitopenia cíclica canina, infecta cães de diferentes países (MOTOI et al., 2001; SANTOS et al., 2009). Entretanto seu vetor ainda encontra-se incerto, sendo descrito em carrapatos da espécie Riphicephalus bursa, R. sanguineus (MOTOI et al., 2001; HARRUS et al., 2010). O encontro de DNA deste agente em $15,7 \%$ dos carrapatos pesquisados denota a importância do carrapato $R$. sanguineus em sua epidemiologia na cidade de Cuiabá, além de fornecer uma análise da distribuição do agente do município, aspecto ainda não realizado na região. Entretanto não comprova a sua competência vetorial já que esta observação pode estar relacionada ao repasto de sangue de cães infectados.

A ocorrência de grande percentagem de carrapatos infectados e de co-infecção entre os agentes pesquisados, associado a distribuição cosmopolita do $R$. sanguineus, demonstra o alto risco de transmissão destes patógenos aos cães da cidade de Cuiabá.

\section{Referências}

AKTAS, M.; ALTAY, K.; DUMANLI, N.; KALKAN, A. Molecular detection and identification of Ehrlichia and Anaplasma species in ixodid ticks. Parasitology Research, v. 104, n. 5, p. 1243-1248, 2009.

ARAGÃO, H. B.; FONSECA, F. Notas de ixodologia VIII. Lista e chave para representantes da fauna ixodológica brasileira. Memórias do Instituto Oswaldo Cruz, Rio de Janeiro, v. 59, n. 2, p. 115-129, 1961.

DANTAS-TORRES, F. The browndog tick, Rhipicephalus sanguineus (Latreille, 1806) (Acari:Ixodidae): from taxonomy to control. Veterinary Parasitology, Amsterdan, v. 152, n. 3-4, p. 173-185, 2008.

HARRUS, S.; PERLMAN-AVRAHAMI, A.; MUMCUOGLU, K. Y.; MORICK, D.; EYAL, O.; BANETH, G. Molecular detection of Ehrlichia canis, Anaplasma bovis, Anaplasma platys, Candidatus Midichloria mitochondrii and Babesia canis vogeli in ticks from Israel. Clinical Microbiology and Infection, France, v. 17, n. 3, p. 459-463, 2010.

INOKUMA, H.; BEPPU, T.; OKUDA, M.; SHIMADA, Y.; SAKATA, Y. Epidemiological survey of Anaplasma platys and Ehrlichia canis using ticks collected from 
dogs in Japan. Veterinary Parasitology, Amsterdan, v. 115, n. 4, p. 343-348, 2003.

INOKUMA, H.; FUJII, K.; MATSUMOTO, K.; OKUDA, M.; NAKAGOME, K.; KOSUGI, R.; HIRAKAWA, M.; ONISHI, T. Demonstration of Anaplasma (Ehrlichia) platys inclusions in peripheral blood platelets of a dog in Japan. Veterinary Parasitology, Amsterdan, v. 110, n. 1-2, p. 145-152, 2002.

MOTOI, Y.; SATOH, H.; INOKUMA, H.; KIYUUNA, T.; MURAMATSU, Y.; UENO, H.; MORITA, C. First detection of Ehrlichia platys in dogs and Ticks in Okinawa, Japan. Microbiology and Immunology, Tokyo, v. 45 , n. 1, p. 89-91, 2001.

MURPHY, G. L.; EWING, S. A.; WHITWORTH, L. C.; CARL FOX, J.; ALAN KOCAN, A. Molecular and serologic survey of Ehrlichia canis, Ehrlichia chaffeensis, and E. ewingii in dogs and ticks from Oklahoma. Veterinary Parasitology, Amsterdan, v. 79, n. 4, p. 325-339, 1998.
SANTOS, F.; COPPEDE, J. S.; PEREIRA, A. L. A.; OLIVEIRA, L. P.; ROBERTO, P. G.; BENEDETTI, R. B. R.; ZUCOLOTO, L. B.; LUCAS, F.; SOBREIRA, L.; MARINS, M. Molecular evaluation of the incidence of Ehrlichia canis, Anaplasma platys and Babesia spp. in dogs from Ribeirão Preto, Brazil. The Veterinary Journal, British, v. 179, n. 1, p. 145-148, 2009.

SILVA, J. N.; ALMEIDA, A. B. P. F.; BOA SORTE, E. C.; FREITAS, A. G.; SANTOS, L. G. F.; AGUIAR, D. M.; SOUSA, V. R. F. Soroprevalência de anticorpos antiEhrlichia canis em cães de Cuiabá, Mato Grosso. Revista Brasileira de Parasitologia Veterinária, Jaboticabal, v. 19, n. 2, p. 108-111, 2010.

SOUSA, V. R. F.; ALMEIDA, A. B. P. F.; BARROS, L. A.; SALES, K. G.; JUSTINO, C. H. S.; DALCIN, L.; BOMFIM, T. C. B. Avaliação clínica e molecular de cães com erliquiose. Ciência Rural, Santa Maria, v. 40, n. 6, p. 1309-1313, 2010. 